International Journal of Biology, Pharmacy and Allied Seiences (IJBPAS) 'A Bridge Betuen Caboratory and Qnendo'

WWW.ijbpas.com

\title{
PATTERN OF DENTAL CARIES IN 2 TO 6 YEAR OLD CHILDREN: A DESCRIPTIVE STUDY
}

\section{SANKAR P ${ }^{1}$, SUBRAMANIAN EMG ${ }^{2 *}$ AND RAVINDRAN $\mathbf{V}^{3}$}

1: Postgraduate, Department of Pedodontics, Saveetha Dental College, Saveetha Dental College and Hospitals, Saveetha Institute of Medical and Technical Sciences, 162, Poonamallee High Road, Chennai 600077, Tamil Nadu, India

2: Professor, Department of Pedodontics, Saveetha Dental College, Saveetha Dental College and Hospitals, Saveetha Institute of Medical and Technical Sciences, 162, Poonamallee High Road, Chennai 600077, Tamil Nadu, India

3: Senior Lecturer, Department of Pedodontics. Saveetha Dental College, Saveetha Dental College and Hospitals, Saveetha Institute of Medical and Technical Sciences, 162, Poonamallee High Road, Chennai 600077, Tamil Nadu, India

*Corresponding Author: E Mail: Dr. EMG Subramanian: subramanian@saveetha.com

Received $19^{\text {th }}$ March 2021; Revised 25 ${ }^{\text {th }}$ April. 2021; Accepted $20^{\text {th }}$ May 2021; Available online $1^{\text {st }}$ Aug. 2021

\section{https://doi.org/10.31032/IJBPAS/2021/10.8.1080}

\section{ABSTRACT}

Background: The distribution of caries on the surface of teeth differs from person to person. Detailed knowledge of caries patterns is important as specific patterns of attack might indicate a distinct etiology. Aim: This study aims to use the Horowitz and Poulsen system to assess the pattern of caries in 2 to 6 year olds and find some insight on the severity and distribution pattern of caries. Materials and methods: This was a hospital based retrospective study. Dental records of 86000 patients who had visited a private dental hospital from June 2019 to March 2020, located in Chennai, Tamil Nadu, India were retrieved manually and analysed. All information including patient ID, age, gender, dmfs, severity zone score were retrieved. All children with chief complaint of dental caries with at least one carious tooth were included.This present study 
was done to determine the pattern of caries in $2-6$ year old children. Results: Out of the total 1469 children treated $54.55 \%$ were males and $45.54 \%$ were females. The total number of patients across various age groups 2 years: 61 (4.15\%), 3 years: $172(11.70 \%), 4$ years: $348(23.68 \%), 5$ years: 425 (28.93\%), 6 years: $462(31.44 \%)$.The overall $\mathrm{dmfs}$ for the study population based on age groups was 2 years: $3.27,3$ years: $5.46,4$ years: $8.59,5$ years: $10.29,6$ years: 10.34 . In the severity zone: out of the 1469 children, severity zone 0: 147 children, severity zone 1: 102 children, severity zone 2: 542 children, severity zone 3: 340 children, severity zone 4: 278 children, severity zone 5: 59 children ( $p$ value $=0.172$ ). Conclusion: We can conclude that there was a significant increase in the severity zone as the $\mathrm{dmfs}$ scores increased with the high severity zone being 2 at around 6 years mostly in male children.

\section{Keywords: Caries pattern; Early childhood caries; Hierarchical system; Primary dentition; Prevalence}

\section{INTRODUCTION}

Currently one of the major dental public health issues is dental caries and it is a chronic disease of childhood [1]. Despite the decline in caries in the past 40 years dental caries in preschool children still remain unchanged [2, 3]. ECC describes dental caries affecting children aged 0-71 months. "According to the American Academy of Pediatric Dentistry (AAPD), ECC is defined as the presence of 1 or more decayed (noncavitated or cavitated lesions), missing (due to caries), or filled tooth surfaces in any primary tooth in a child 71 months old or younger. Today, the more commonly used terms are ECC and S-ECC in severe cases [4]. This unique pattern of dental caries affecting the primary maxillary incisor and first molar teeth and sparing the mandibular incisor teeth in most cases is thought to be related to the chronology of primary tooth eruption and subsequent acquisition of cariogenic bacteria, namely mutans streptococci [5].

One very important factor for the increased incidence of ECC is due to dental neglect. The lack of parent's or guardian's attention will have a negative influence on the child's oral status. Thus, the interventions must also be directed toward parents' beliefs and attitudes about oral health [6].

The prevalence of ECC is reported as between $1 \%$ and $12 \%$ in most developed countries [7] and $85 \%$ in disadvantaged groups in developing countries [8]. In a systematic review, it is presented that the prevalence of ECC varies from $2.1 \%$ in 
Sweden to $85.5 \%$ in rural Chinese children [9]. Some of the highest prevalence of ECC have been reported in some Middle Eastern countries, such as Palestine $(76 \%)$ and the United Arab Emirates (83\%) [10, 11]. Surprisingly analysis of all indian studies revealed the overall prevalence of ECC in India to be $49.6 \%$. Andhra Pradesh was found to have the highest prevalence of ECC at $63 \%$, and the lowest prevalence was reported in Sikkim $(41.92 \%)$. This review has reported a high prevalence of ECC in India. None of the states reported prevalence below $40 \%$ with Tamil Nadu having prevalence of $55.73 \%$ [12].

Detailed knowledge of caries patterns is important as specific patterns of attack might indicate a distinct etiology [13]. Various surveys on caries epidemiology have evaluated prevalence and severity of caries but not the caries distribution pattern [1416].

We cannot forget the fact that caries in primary teeth pose a high risk in permanent dentition. The distribution of caries on the surface of teeth differs from person to person. Previous study reports that this follows a typical pattern [1] with the $2^{\text {nd }}$ primary molar being most affected [17-19]. All teeth and all surfaces are susceptible to caries. So it is important we know the relative caries susceptibility of the teeth in the maxillary and mandibular arch [18]. In certain ethnic groups, children with caries before 2.5 years of age usually have decayed smooth surfaces of maxillary incisors and occlusal fissures of the first molar teeth [20, 21]

Most of the prevalence and dental caries status was found using DMFT/DMFS initially introduced by Knutson, Klein and Palmer 1988. This index was only a measure of cumulative prevalence of dental disease; it does not indicate the severity of disease [22]. Grainer was the first to suggest a hierarchical system which was later modified by Horowitz and Poulson and can be used to describe the severity of caries by finding the caries pattern. In this study we use this newer system to assess the pattern of caries in 2 to 6 year olds and thereby find some insight on the severity and distribution pattern of caries.

\section{MATERIALS AND METHODS}

This is a private hospital based retrospective study. It was done by two examiners. Simple random sampling was done to reduce sampling bias. Dental records of 86000 patients who had visited a private dental hospital from June 2019 to March 2020, located in Chennai, Tamil Nadu, India were retrieved manually and analysed. All information including patient ID, age, 
gender, dmfs, severity zone score were retrieved.

On the basis of the caries recordings, the $\mathrm{dmfs}$ score of each child was calculated and each child was assigned to one of the six zones of increasing caries severity, ranging from 0 (caries free) to 5 (most severe) [Table 1]. This hierarchical system works on an assumption of cumulative zone membership, i.e., it assumes that once a child is classified into a given severity zone, it will automatically belong to all zones of lesser severity (excluding severity zone 0 ). Thus, the zones in the system are mutually exclusive.

All the procedures were done by only a single operator for a specific patient. A signed written and video informed consent was obtained from the parents/guardian of the children prior to examination. A full mouth examination with intraoral periapical radiographs was done. Caries examination was done using a plain mouth mirror, William's periodontal index probe, under optimal light source. Each surface was scored independently. Erupted permanent teeth were excluded from this analysis. Each child was examined either sitting on a dental chair or on the lap of the parent or knee to knee position depending on the behaviour and age of the child. The probe was sparingly used on doubtful surfaces.

All children with chief complain of dental caries with at least one carious tooth were included. Children with systemic disorders, special children who had primary central incisors indicated for extraction and caries free children were excluded. Cross verification for incomplete and inaccurate data was cross checked with radiographs and intraoral photographs and verified. The sample was representative with specific inclusion and exclusion made it internally valid. This study had validity externally limited to the South Indian population due to limited geographic inclusion.

\section{Ethical aspect}

This study was conducted with ethical approval from the Institutional Review Board (Ethical approval number: SDC/SIHEC/2020/DIASDATA/0619-0320

of Saveetha Institute of Medical And Technical Sciences.

\section{Statistical Analyses}

The collected data was entered into Microsoft office Excel 2013 datasheet transferred to SPSS version 26.0 software (SPSS software Chicago, IL, USA) for statistical analysis. The independent variables: gender, age. The independent variables: total number of procedures, cost of 
procedures, treatment done. They were put to descriptive analysis, mean and standard deviation. . The Pearson correlation test was done between dmfs and SZS scores to check for correlation between the two categorical variables.

\section{RESULTS AND DISCUSSION}

This present study was done to determine the pattern of caries in $2-6$ year old children. The total number of patients across various age groups 2 years: $61(4.15 \%), 3$ years: 172 (11.70\%), 4 years: $348(23.68 \%), 5$ years: 425 (28.93\%), 6 years: 462 (31.44\%) [Figure 1]. The comparison in age shows a high caries rate 6 years and there is a gradual increase. This can be attributed to the long retention time of the tooth in the oral cavity, highest caries prevalence, and increase in snacking time. It has also been noted though with an increased frequency of snacking children with malnutrition were more likely to develop dental caries than those with normal weight or high BMI [23]. Out of the total 1469 children treated $793(54.55 \%)$ were males and $675(45.54 \%)$ were females

\section{[Figure 2].}

Distribution of caries experience across various age groups: In the severity zone: out of the 1469 children, severity zone 0: 147 children, severity zone 1: 102 children, severity zone 2: 542 children, severity zone
3: 340 children, severity zone 4: 278 children, severity zone 5: 59 children [Figure 3].

Dmfs values based on gender was 8.79 in males and 6.85 in females. Chi square test was done and the association was found to be significant (Pearson chi square value: 51.074, $\mathrm{p}$ value $=0.001)$ [Figure 4]

Dmfs values based on age groups were 2 years: $2.12,3$ years: $4.56,4$ years: $10.37,5$ years: $12.31,6$ years: 10.98 . Chi square test was done and the association was found to be not significant (Pearson chi square value: 69.000, $p$ value $=0.172)$ [Figure 5]

Distribution of Dmfs values across various severity zones severity zone $0: 0.47$, severity zone 1: 2.6, severity zone 2: 6.13, severity zone $3: 8.55$, severity zone $4: 11.27$, severity zone 5: 14.93. Chi square test was done and the association was found to be significant (Pearson chi square value: $127.000, p$ value $=$ 0.002) [Figure 6].

Dental caries is one of the major oral health problems in both industrialized and increasing in developing countries and it affects 60 to $90 \%$ school aged children and adults [24]. The prevalence of dental caries varies from $33.7 \%$ to $90 \%$ in the child population and is increasing at an alarming rate [25-28]. 
The overall dmfs for the study population indicated a serious oral health problem. The distribution of children according to severity zones indicated a very low percentage of caries free children and high percentage of children with caries in severity zone 2 which makes proximal surface of posterior teeth (including the distal surface of cupids) more susceptible [29-31]. This can be due to the plaque retention in posterior teeth, improper salivary flow to the lingual aspect of the teeth due to tongue obstruction due to high frenal attachment [32], due to any salivary pathologies like salivary calculi, ranula [33] etc.

It was observed that mean dmfs scores for these children which were assigned severity zone 0 was 0.47 rather than 0 . This finding was consistent with the previous study [22, 29]. This was due to the discrepancy due to the fact that according to the criteria the buccal and lingual surfaces of the posterior teeth and lingual surface of anterior teeth were excluded when assigning severity zones. But while counting dmfs all surfaces were counted.

Out of 1469 children around $75.8 \%$ children had occlusal caries and $51.2 \%$ children had proximal and the occlusal surface of the posterior teeth affected. Decay in the anterior most commonly followed the maxillary arch
[34]. The carious involvement of specific teeth was explained in part by anatomic features such as occlusal lesions in primary molars, high level caries in first molars distal surfaces due to frequently close contact between first and second molars and this enamel $[35,36]$.

At an individual level contralateral homologous teeth or surfaces showed similar patterns in the distribution of carious lesions meaning an equal probability of developing caries or random distribution of decay as defined previously [37]. This also shows that caries is an asymmetric disease [34] and follows surface - surface patterns theory [38].

This data can be used by dentists to identify high risk patients and implement preventive programs. Few of the limitations to this study was the restricted geographic location and small sample size. Population-based early childhood health systems hold great potential to reduce the burden of ECC, improve health care efficiency and cost-effectiveness. Though treatment ranges from oral prophylaxis [39], restorations, pulp therapies $[\mathbf{4 0}-\mathbf{4 6}]$ in the oral cavity and management of any trauma to the dentition [47] etc. Early non-operative interventions by the dental professionals, including plaque removal [48], application of topical fluoride $[49,50]$, and usage of sealants, are accepted as important steps for preventing ECC. 
Table 1: Poulsen and Horowitz criteria to classify individuals according to severity of dental caries

\begin{tabular}{|c|c|}
\hline Severity Zone & Definition (Surfaces involved) \\
\hline $\mathbf{0}$ & None of the above \\
\hline $\mathbf{1}$ & Pit and fissure surfaces of posterior teeth and labial surfaces of maxillary cuspids \\
\hline 3 & Proximal surfaces of molars (including distal surfaces of cuspids) \\
\hline 4 & Proximal surfaces of maxillary anterior teeth (excluding distal surfaces of cuspids) \\
\hline 5 & Labial surfaces of maxillary and mandibular incisor and cuspids (excluding those of \\
maxillary cuspids)
\end{tabular}

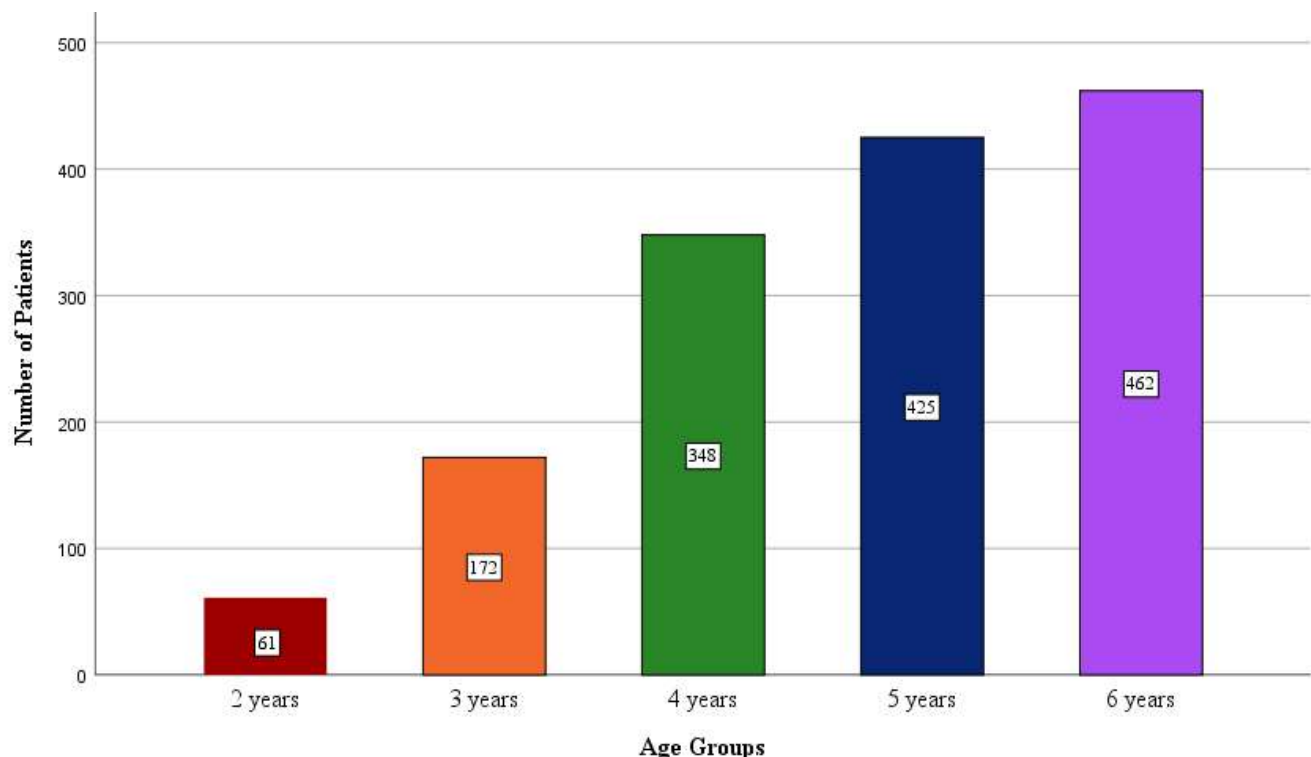

Figure 1: Bar graph showing distribution across various age groups. $X$ - axis represents the various age groups and the $y$ axis represents the number of patients. Maroon color represents 2 year olds, orange color represents 3 year olds, dark green color represents 4 year olds, dark blue color represents 5 year olds, violet color represents 6 year olds. This graph shows that the most number of treatments was done for 6 years old children $(31.44 \%$, violet).

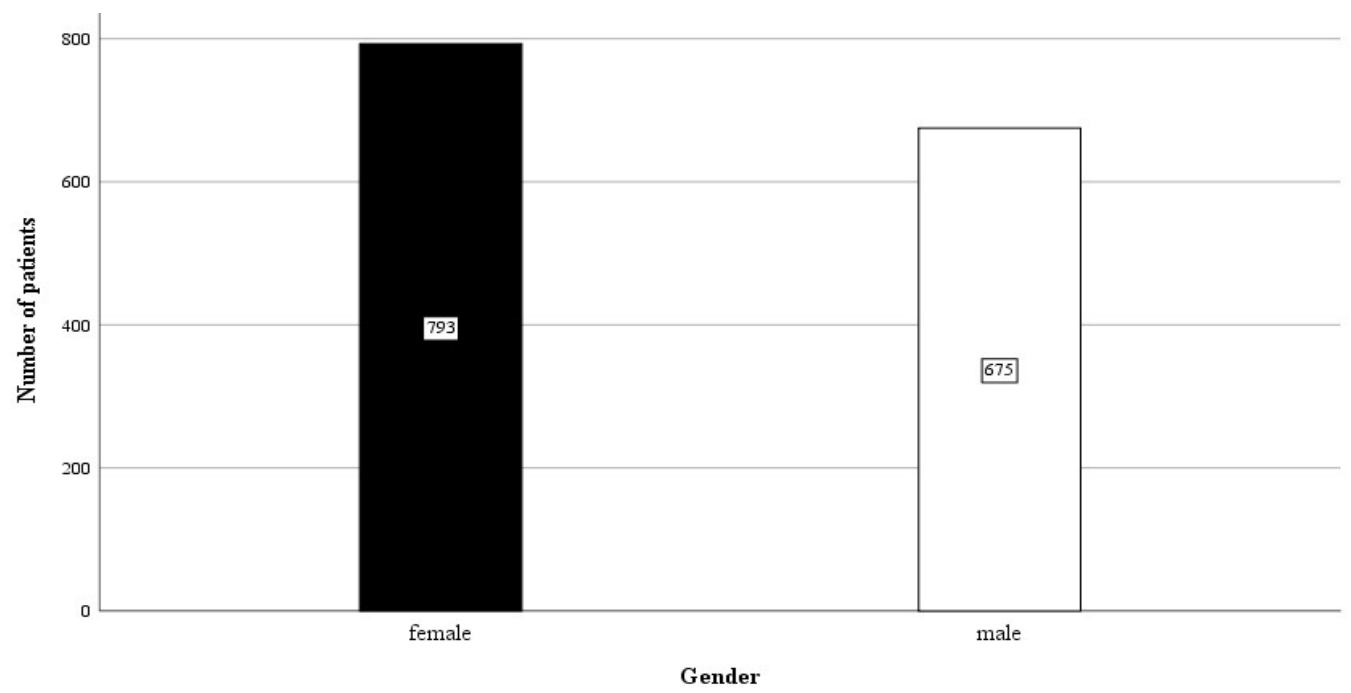

Figure 2: Bar graph showing the distribution of patients based on gender. $X$ - axis represents gender and $\mathbf{y}$ - axis represents the number of patients. Females are represented in black and males are represented in white color. This graph shows that male patients $793(54.55 \%$, white) were more as compared to female patients 675 (45.54\%, black). 


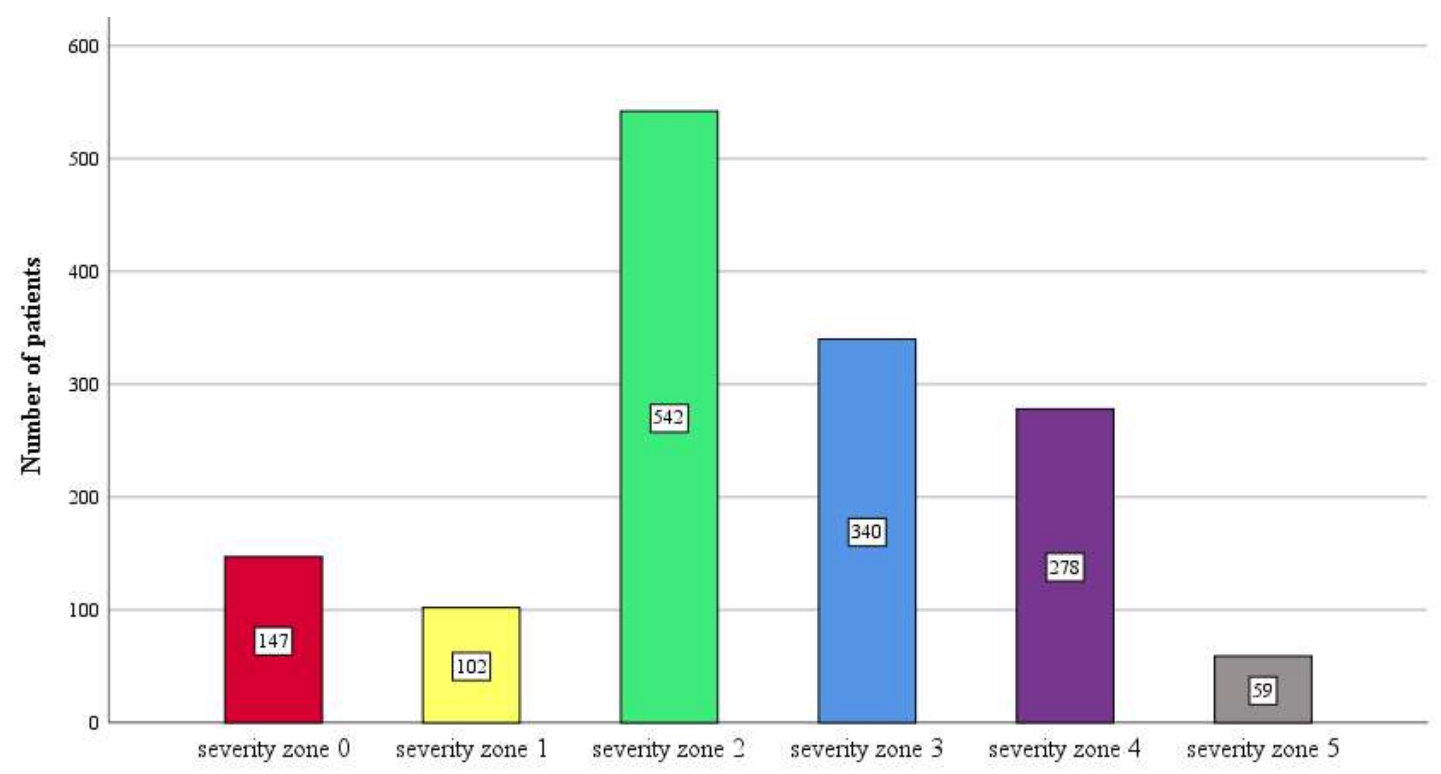

Severity zone

Figure 3: Bar graph showing distribution of caries experience across various age groups. $X$ - axis represents the severity zone and the $y$ - axis represents the number of patients. Red color represents severity zone 0 , yellow color represents severity zone 1 , light green color represents severity zone 2 , light blue color represents severity zone 3 , plum color represents severity zone 4 , grey color represents severity zone 5 . This graph shows that the most number of children fall under the severity zone 2 (542 children, light green).

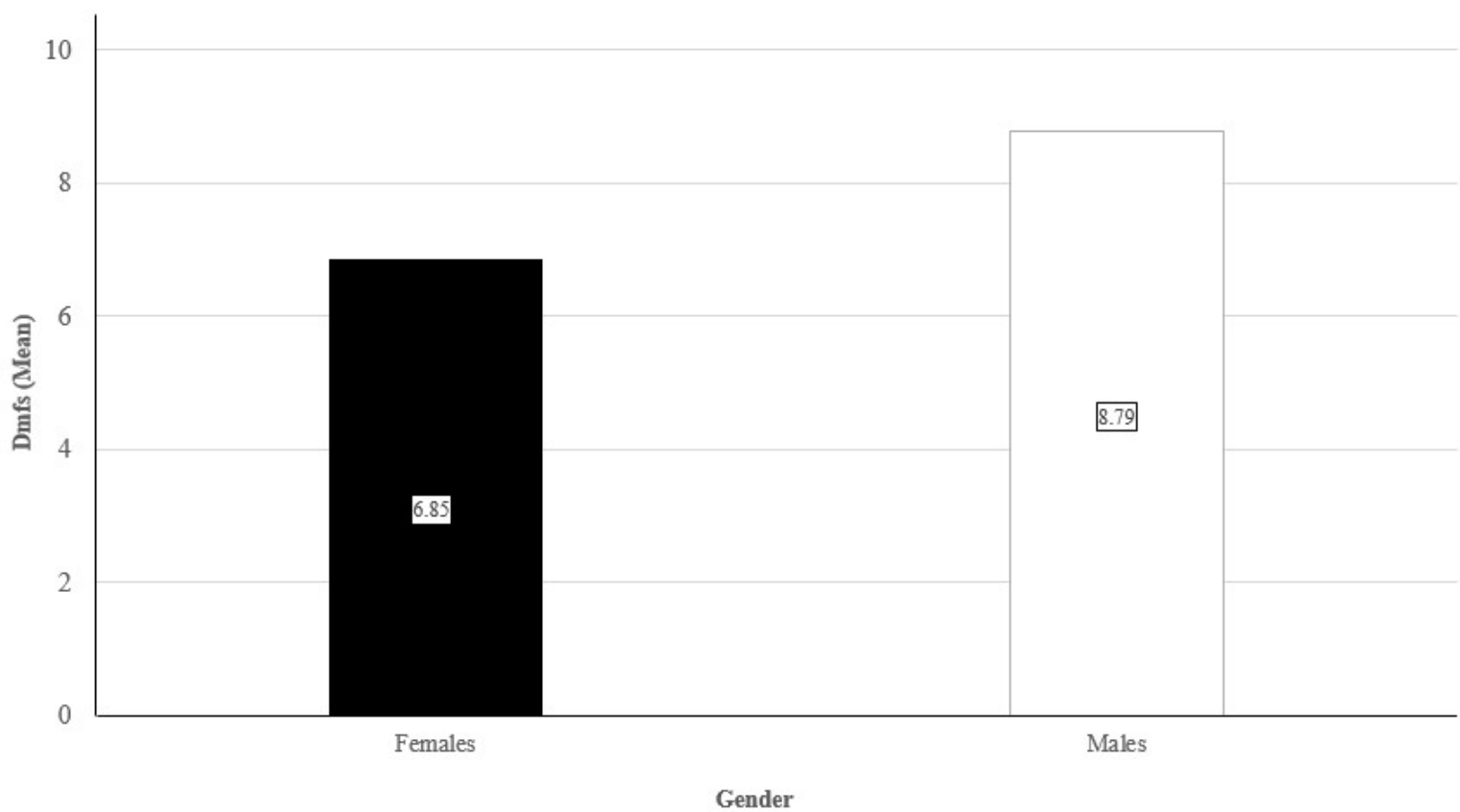

Figure 4: Bar graph showing distribution of mean dmfs values based on gender. $X$ - axis represents the gender and the $y$ - axis represents the mean dmfs values. Females are represented in black and males are represented in white color. Chi square test was done and the association was found to be significant (Pearson chi square value: 51.074, $p$ value $=0.001$ ).

The dmfs values for males were more $(8.79$, white) as compared to females $(6.85$, black) and this was statistically significant. 


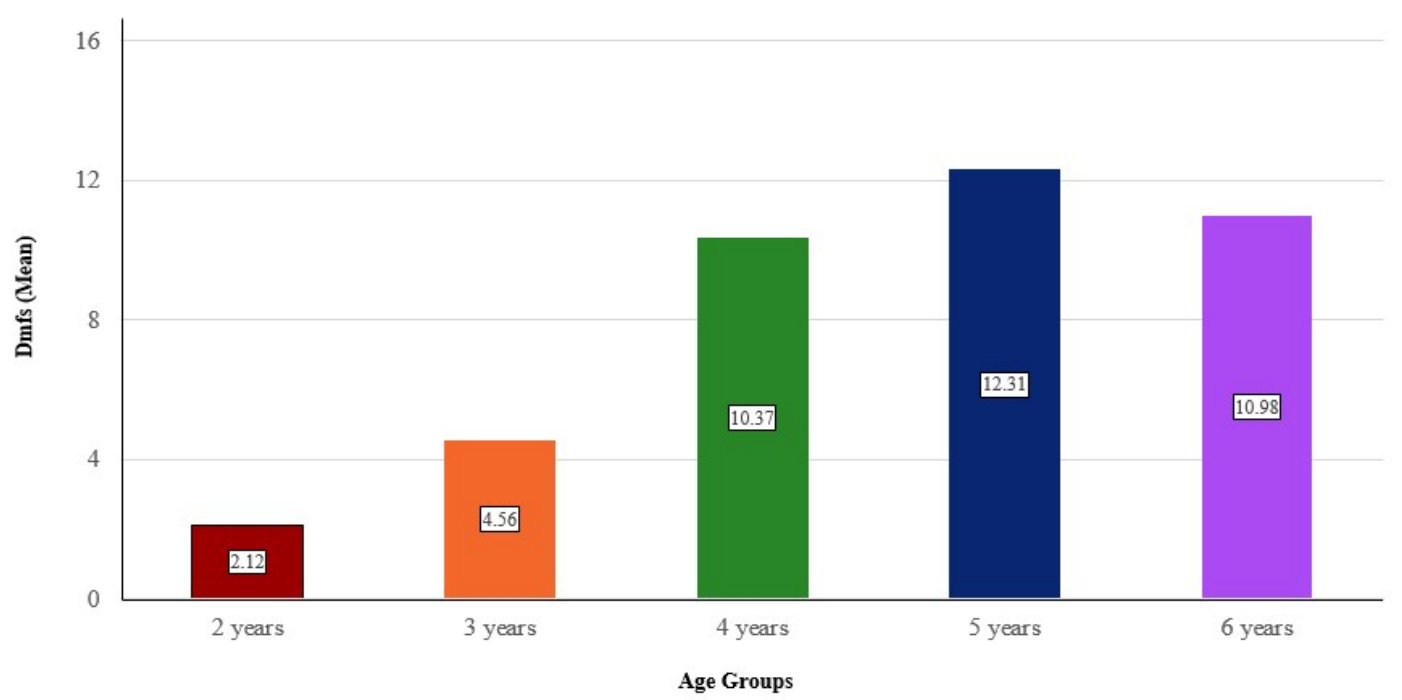

Figure 5: Distribution of mean $\mathrm{dmfs}$ values across various age groups. $X$ - axis represents the various age groups and the $\mathrm{y}$ - axis represents the mean dmfs values. Maroon color represents 2 year olds, orange color represents 3 year olds, dark green color represents 4 year olds, dark blue color represents 5 year olds, violet color represents 6 year olds. Chi square test was done and the association was found to be not significant (Pearson chi square value: 69.000, $p$ value $=0.172$ ). This graph showed that it was the mean dmfs values was highest in 5 year olds (12.31, dark blue) but was not statistically significant.

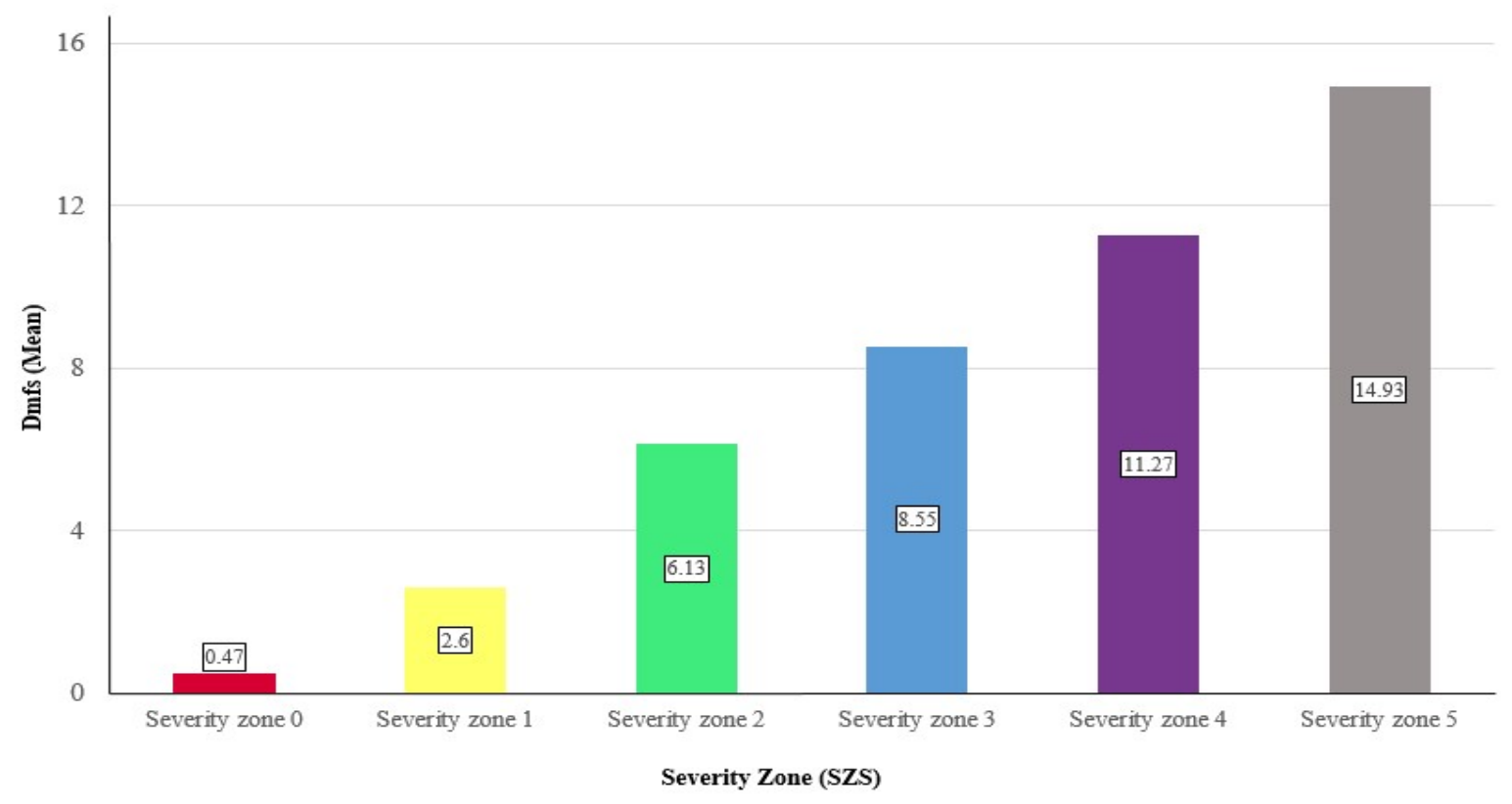

Figure 6: Bar graph showing distribution of mean dmfs values for the various severity zones. $X$ - axis represents the various severity zones and the $\mathrm{y}$ - axis represents the mean $\mathrm{dmfs}$ values. Red color represents severity zone 0 , yellow color represents severity zone 1 , light green color represents severity zone 2 , light blue color represents severity zone 3, plum color represents severity zone 4 , grey color represents severity zone 5 . Chi square test was done and the association was found to be significant (Pearson chi square value: 127.000 , $p$ value $=0.002$ ). This graph shows that the dmfs values increase, with the increase in the severity zones and this was statistically significant. 


\section{CONCLUSION}

Within the limits of the study we can conclude that there was a significant increase in the severity zone as the $\mathrm{dmfs}$ scores increased with the high severity zone being 2 at around 6 years mostly in male children as compared to female children.

\section{Financial support and sponsorship:}

Nil.

\section{Conflicts of interest:}

There are no conflicts of interest.

\section{REFERENCES}

[1] Psoter WJ, Zhang H, Pendrys DG, Morse DE, Mayne ST. Classification of dental caries patterns in the primary dentition: a multidimensional scaling analysis. Community Dent Oral Epidemiol. 2003 Jun;31(3):231-8.

[2] Pitts NB, Chestnutt IG, Evans D, White D, Chadwick B, Steele JG. The dentinal caries experience of children in the United Kingdom, 2003. Br Dent J. 2006 Mar 25;200(6):313-20.

[3] Hugoson A, Koch G, Helkimo AN, Lundin $\mathrm{S}-\AA \AA$. Caries prevalence and distribution in individuals aged 3-20 years in Jönköping, Sweden, over a 30-year period (1973-2003) [Internet]. Vol. 0, International Journal of Paediatric Dentistry. 2007. p. 071119221239001 - ??? Available from: http://dx.doi.org/10.1111/j.1365$263 x .2007 .00874 . x$

[4] Edem AP. Early Childhood Caries Update
[Internet]. Dental Caries - Diagnosis, Prevention and Management. 2018. http://dx.doi.org/10.5772/intechopen.76300

[5] Hallett KB, O'Rourke PK. Pattern and severity of early childhood caries [Internet]. Vol. 34, Community Dentistry and Oral Epidemiology. 2006. p. 25-35. Available from: $\quad h t t p: / / d x . d o i . o r g / 10.1111 / j .1600-$ 0528.2006.00246.x

6] Gurunathan D, Shanmugaavel AK. Dental neglect among children in Chennai. J Indian Soc Pedod Prev Dent. 2016 Oct;34(4):3649.

[7] Congiu G, Campus G, Lugliè PF. Early Childhood Caries (ECC) Prevalence and Background Factors: A Review. Oral Health Prev Dent. 2014;12(1):71-6.

[8] Thitasomakul S, Thearmontree A, Piwat S, Chankanka O, Pithpornchaiyakul W, Teanpaisan R, et al. A longitudinal study of early childhood caries in 9- to 18-month-old Thai infants. Community Dent Oral Epidemiol. 2006 Dec;34(6):429-36.

[9] Ismail AI, Sohn W. A systematic review of clinical diagnostic criteria of early childhood caries. J Public Health Dent. 1999 Summer;59(3):171-91.

[10] Azizi Z. The Prevalence of Dental Caries in Primary Dentition in 4- to 5-Year-Old Preschool Children in Northern Palestine [Internet]. Vol. 2014, International Journal of Dentistry. 2014. p. 1-5. Available from: http://dx.doi.org/10.1155/2014/839419

[11] El-Nadeef MAI, Hassab H, Al-Hosani E. 
National survey of the oral health of 5-yearold children in the United Arab Emirates. East Mediterr Health J. 2010 Jan;16(1):515.

[12] Ganesh A, Muthu MS, Mohan A, Kirubakaran R. Prevalence of Early Childhood Caries in India--A Systematic Review. Indian J Pediatr. 2019;86(3):27686.

[13] Ferro R, Besostri A, Olivieri A. Caries prevalence and tooth surface distribution in a group of 5-year-old Italian children [Internet]. Vol. 10, European Archives of Paediatric Dentistry. 2009. p. 33-7. Available from: http://dx.doi.org/10.1007/bf03262665

[14] Ferro R, Besostri A, Meneghetti B, Stellini E. Prevalence and severity of dental caries in 5- and 12-year old children in the Veneto Region (Italy). Community Dent Health. 2007 Jun;24(2):88-92.

[15] Ferro R, Besostri A, Olivieri A, Stellini E, Mazzoleni S. Preschoolers' dental caries experience in and its trend over 20 years in a North-East Italian Health district. Eur J Paediatr Dent. 2007;8(4):199.

[16] Ferro R, Besostri A, Meneghetti B. Dental caries experience in preschool children in Veneto region (Italy). Community Dent Health. 2006 Jun;23(2):91-4.

[17] Gizani S, Vinckier F, Declerck D. Caries pattern and oral health habits in 2- to 6year-old children exhibiting differing levels of caries. Clin Oral Investig. 1999
Mar;3(1):35-40.

[18] Saravanan S, Madivanan I, Subashini B, Felix JW. Prevalence pattern of dental caries in the primary dentition among school children [Internet]. Vol. 16, Indian Journal of Dental Research. 2005. p. 140. Available from: http://dx.doi.org/10.4103/0970-9290.29907

[19] Wyne AH. Caries prevalence, severity, and pattern in preschool children. $\mathrm{J}$ Contemp Dent Pract. 2008 Mar 1;9(3):24-31.

[20] Wendt LK, Hallonsten AL, Koch G. Dental caries in one- and two-year-old children living in Sweden. Part I--A longitudinal study. Swed Dent J. 1991;15(1):1-6.

[21] Grindefjord M, Dahllöf G, Ekström G, Höjer B, Modéer T. Caries prevalence in 2.5-year-old children. Caries Res. 1993;27(6):505-10.

[22] Wong MC, Schwarz E, Lo EC. Patterns of dental caries severity in Chinese kindergarten children. Community Dent Oral Epidemiol. 1997 Oct;25(5):343-7.

[23] Cheng Y-H, Liao Y, Chen D-Y, Wang Y, $\mathrm{Wu}$ Y. Prevalence of dental caries and its association with body mass index among school-age children in Shenzhen, China. BMC Oral Health. 2019 Dec 4;19(1):270.

[24] Petersen PE, Bourgeois D, Ogawa H, Estupinan-Day S, Ndiaye C. The global burden of oral diseases and risks to oral health. Bull World Health Organ. 2005 Sep;83(9):661-9.

[25] Rao A, Sequeira SP, Peter S. Prevalence of 
dental caries among school children of Moodbidri. J Indian Soc Pedod Prev Dent. 1999 Jun;17(2):45-8.

[26] Joshi N, Rajesh R, Sunitha M. Prevalence of dental caries among school children in Kulasekharam village: a correlated prevalence survey. J Indian Soc Pedod Prev Dent. 2005 Sep;23(3):138-40.

[27] David J, Wang NJ, Astrøm AN, Kuriakose S. Dental caries and associated factors in 12-year-old schoolchildren in Thiruvananthapuram, Kerala, India. Int $\mathrm{J}$ Paediatr Dent. 2005 Nov;15(6):420-8.

[28] Shetty NS, Tandon S. Prevalence of dental caries as related to risk factors in schoolchildren of South Kanara. J Indian Soc Pedod Prev Dent. 1996 Mar 1;14(1):30.

[29] Chandan GD, Saraf S, Sangavi N, Khatri A. Pattern of dental caries in 3-6-year-old children using decayed, missing, filled surface index and hierarchical caries pattern system: A descriptive study. J Indian Soc Pedod Prev Dent. 2018 Apr;36(2):108-12.

[30] Saraf S, Chandan GD, Sangavi N, Khatri A. Pattern of dental caries in 3-6-year-old children using decayed, missing, filled surface index and hierarchical caries pattern system: A descriptive study [Internet]. Vol. 36, Journal of Indian Society of Pedodontics and Preventive Dentistry. 2018. p. 108. Available from: http://dx.doi.org/10.4103/jisppd.jisppd_118 3_17

[31] Holt RD. The pattern of caries in a group of 5-year-old children and in the same cohort at 9 years of age. Community Dent Health. 1995 Jun;12(2):93-9.

[32] Christabel SL, Gurunathan D. Prevalence of Type of Frenal Attachment and Morphology of Frenum in Children, Chennai, Tamil Nadu [Internet]. Vol. 6, World Journal of Dentistry. 2015. p. 203-7. http://dx.doi.org/10.5005/jp-journals10015-1343

[33] Packiri S, Gurunathan D, Selvarasu K. Management of Paediatric Oral Ranula: A Systematic Review. J Clin Diagn Res. 2017 Sep;11(9):ZE06-9.

[34] Vanobbergen J, Lesaffre E, García-Zattera MJ, Jara A, Martens L, Declerck D. Caries patterns in primary dentition in 3-, 5- and 7year-old children: spatial correlation and preventive consequences. Caries Res. 2007;41(1):16-25.

[35] Dunning JM. Principles of Dental Public Health. Harvard University Press; 1986. $695 \mathrm{p}$.

[36] Elfrink MEC, Veerkamp JSJ, Kalsbeek H. Caries pattern in primary molars in Dutch 5-year-old children. Eur Arch Paediatr Dent. 2006 Dec;7(4):236-40.

[37] Hujoel PP, Lamont RJ, DeRouen TA, Davis S, Leroux BG. Within-subject coronal caries distribution patterns: an evaluation of randomness with respect to the midline. $\mathrm{J}$ Dent Res. 1994 Sep;73(9):1575-80.

[38] Johnsen DC, Schubot D, Bhat M, Jones PK. Caries pattern identification in primary 
dentition: a comparison of clinician assignment and clinical analysis groupings.

Pediatr Dent. 1993 Mar;15(2):113-5.

[39] Subramanyam D, Gurunathan D, Gaayathri R, Vishnu Priya V. Comparative evaluation of salivary malondialdehyde levels as a marker of lipid peroxidation in early childhood caries. Eur J Dent. 2018 Jan;12(1):67-70.

[40] Jeevanandan G. Kedo-S Paediatric Rotary Files for Root Canal Preparation in Primary Teeth - Case Report. J Clin Diagn Res. 2017 Mar;11(3):ZR03-5.

[41] Govindaraju L, Jeevanandan G, Subramanian EMG. Comparison of quality of obturation and instrumentation time using hand files and two rotary file systems in primary molars: A single-blinded randomized controlled trial. Eur J Dent. 2017 Jul;11(3):376-9.

[42] Govindaraju L, Jeevanandan G, Subramanian EMG. Knowledge and practice of rotary instrumentation in primary teeth among indian dentists: A questionnaire survey [Internet]. Vol. 9, Journal of International Oral Health. 2017. p. 45.4 Available from: http://dx.doi.org/10.4103/jioh.jioh_4_17

[43] Jeevanandan G, Govindaraju L. Clinical comparison of Kedo-S paediatric rotary files vs manual instrumentation for root canal preparation in primary molars: a double blinded randomised clinical trial [Internet]. Vol. 19, European Archives of
Paediatric Dentistry. 2018. p. 273-8. Available from: http://dx.doi.org/10.1007/s40368-018-03566

[44] Govindaraju L. Clinical Evaluation of Quality of Obturation and Instrumentation Time using Two Modified Rotary File Systems with Manual Instrumentation in Primary Teeth [Internet]. JOURNAL OF CLINICAL AND DIAGNOSTIC RESEARCH. 2017. Available from: http://dx.doi.org/10.7860/jcdr/2017/30069.1 0602

[45] Panchal V, Jeevanandan G, Subramanian EMG. Comparison of instrumentation time and obturation quality between hand $\mathrm{K}$-file, $\mathrm{H}$-files, and rotary Kedo-S in root canal treatment of primary teeth: A randomized controlled trial [Internet]. Vol. 37, Journal of Indian Society of Pedodontics and Preventive Dentistry. 2019. p. 75. Available from:

http://dx.doi.org/10.4103/jisppd.jisppd_72_ 18

[46] Nair M, Jeevanandan G, Vignesh R, Subramanian EMG. Comparative evaluation of post-operative pain after pulpectomy with k-files, kedo-s files and mtwo files in deciduous molars -a randomized clinical trial. Brazilian Dental Science. 2018 Oct 24;21(4):411-7.

[47] Ravikumar D, Jeevanandan G, Subramanian EMG. Evaluation of knowledge among general dentists in treatment of traumatic 
injuries in primary teeth: A cross-sectional questionnaire study. Eur J Dent. 2017 Apr;11(2):232-7.

[48] Govindaraju L, Gurunathan D. Effectiveness of Chewable Tooth Brush in Children-A Prospective Clinical Study. J Clin Diagn Res. 2017 Mar;11(3):ZC31-4.

[49] Ramakrishnan M, Bhurki M. Fluoride,
Fluoridated Toothpaste Efficacy And Its Safety In Children - Review. International Journal of Pharmaceutical Research. 2018;10(04):109-14.

[50] Somasundaram S, Ravi K, Rajapandian K, Gurunathan D. Fluoride Content of Bottled Drinking Water in Chennai, Tamilnadu. J Clin Diagn Res. 2015 Oct;9(10):ZC32-4. 